\title{
1. Economy and energy in Mediterranean countries
}

\section{ECONOMY AND POPULATION}

The Mediterranean countries differ greatly in their institutions, economies and energy consumption. The Mediterranean is an ancient crossroads comprising 25 countries that are part of the Middle East, North Africa, the European Union (EU) and candidate countries to the EU. The 25 Mediterranean countries have many common characteristics but also differ substantially from an economic, cultural, religious and social perspective. Regional inequalities, associated with problems of political instability, wars and serious internal unrest, are fuelling ever-increasing migratory flows from the southern countries, especially from Syria and Libya, but also from Egypt, Morocco, Algeria and Tunisia, towards the richer and safer European countries. Within the Mediterranean region the following six macroareas may be identified: the Latin area, the Adriatic area, the Anatolian-Balkan area, the Middle Eastern area, the LibyanEgyptian area and the Maghreb. The Latin area includes Portugal, Spain, France, Italy and Malta; the Adriatic includes Slovenia, Croatia, Bosnia and Herzegovina, Serbia, Montenegro, Macedonia and Albania; the AnatolianBalkan area comprises Greece, Turkey and Cyprus; in the Middle Eastern area are Syria, Lebanon, Israel, Palestine and Jordan; the Libyan-Egyptian area consists of Egypt and Libya; while the Maghreb comprises Tunisia, Algeria and Morocco (Bartoletto, 2016a). The differences are evident both in terms of economic development, and from a demographic standpoint (Capasso, 2018; Zupi, 2017). Indeed, the four main countries of the Latin area, namely France, Italy, Spain and Portugal, account for only $37 \%$ of the total population of Mediterranean countries, and yet produce $70 \%$ of the total gross domestic product (GDP) and consume $60 \%$ of energy.

The total population of the Mediterranean region is about 529 million, amounting to roughly $7 \%$ of the world's population. The most populous country is Egypt, with 95.7 million inhabitants, followed by Turkey (78.2 million), France (66.9 million) and Italy (60.6). Taken together, these four countries account for $56.9 \%$ of the total Mediterranean population. The remaining $43 \%$ is distributed among the other 21 countries. Since the early 
1970s until today the population growth has been very rapid, despite the unrest and outright conflict that have occurred in the former Yugoslavia and Syria, Libya and other countries of the Middle East and the Maghreb. The population has risen from 306 million in 1971 to 529 million in 2016, the growth being mainly from North African and Middle Eastern countries, while the more advanced European countries have witnessed a sharp reduction in growth rates (Figure 1.1). For example, the North African population has more than doubled, growing from 74 million to 189 million, and Egypt's population has almost tripled, increasing from 35.9 million in 1971 to 95.7 million in 2016 (Table 1A.2). Over the same period, in Algeria the population has more than doubled, from 15 million to 40.6 million. The same applies to Morocco, where the population has increased from 16.3 million to 35.3 million. The population of North Africa and the Middle East is expected to increase significantly in the coming decades, while the population growth rates of European countries will continue to decline (Zupi, 2017).

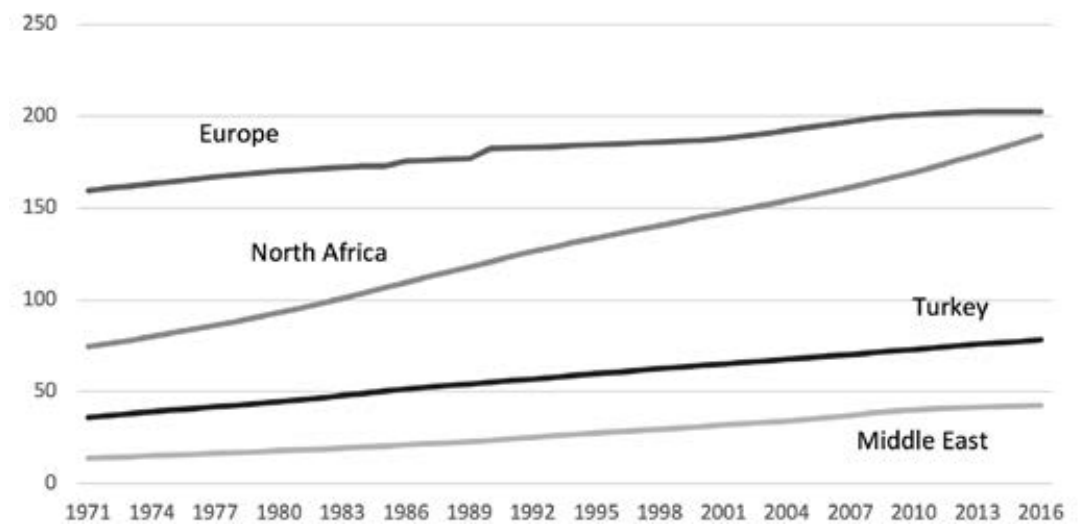

Figure 1.1 Population by macroarea in the Mediterranean region, 1971-2016 (millions)

Source: Our calculations based on IEA, Indicators for $\mathrm{CO}_{2}$ Emissions, data extracted on 21 December 2018.

The population factor is very important for security of energy supply: a population increase in countries with oil and gas reserves means a reduction in exportable surplus due to the increase in domestic demand. For example, from being a net exporter of energy, Egypt has become a net importer. By around 2050 the urban population in Mediterranean coastal regions, particularly in coastal cities, is expected to have doubled. Apart from the megapoleis of 
Cairo and Istanbul, which are among the largest cities in the world, about $18 \%$ of city dwellers live in 85 medium-sized cities, and about half in over 3000 towns with a population of less than 300000 (Blue Plan, 2012). Typical of the Mediterranean region are the dichotomies between urban and rural areas, the inaccessibility of some areas, and the coastal population density.

The concentration of population in coastal zones is higher in the southern Mediterranean countries. In the countries of North Africa $90 \%$ of the inhabitants live in less than $10 \%$ of the available area and almost $40 \%$ of the population live within $50 \mathrm{~km}$ of the coast, with enormous implications in terms of urbanization and vulnerability to possible impacts of climate change. In the Mediterranean region, the growth of urbanization from 1950 to 1995 was very marked (Blue Plan, 2001). During that period, the countries showing the highest urbanization rates were Libya and Turkey. The spectacular growth of cities in Libya has been linked to a profound change in the economy brought about by income from oil. Libya is almost all desert or semi-desert, with a small population that the central government has sought to settle in coastal cities. Yet the growth of such settlements holds out the prospect of worsening environmental problems due to higher energy consumption and $\mathrm{CO}_{2}$ emissions, excessive land consumption, aquifer pollution, inefficient waste management and the cumulative effect of all these factors on the environment and human health.

Under the combined effect of demographic pressure and economic growth, the region is witnessing a sharp increase in energy demand, especially for electricity. Demand is expected to rise four to five times faster in the Southern and Eastern Mediterranean Countries (SEMCs) f $_{\text {than }}$ in the countries on the northern shore (Blue Plan, 2012). Energy is one of the main factors which leads to an increase in urban ecological footprint, and the growth of the number and size of cities is one of the main factors behind rising energy consumption. In the SEMCs the fossil fuel dependency of countries and hence of cities has reached $90 \%$. The growing consumption of oil products is closely linked to development in the transport sector. The increasing production of electricity from fossil fuels, which is the response to growing demand for electricity driven mainly by the intensive use of electrical equipment, is set to continue especially in North Africa and Middle Eastern countries over the coming years.

There are large divides within the Mediterranean region not only with regard to population dynamics, but also from an economic perspective: the more affluent countries that are part of the EU, namely Malta, France and Italy, followed by Slovenia, Spain, Portugal and Greece, contrast with their developing counterparts on the eastern shores and especially those on the southern shores, namely Algeria, Egypt, Libya and Morocco (Figure 1.2). In Syria, in 2010, per capita GDP was about $\$ 6300$, but as a result of the ongoing war, the economy has been devastated, and by 2016 per capita GDP had plunged to $\$ 1842$ (all 
amounts in US dollars). Also in Libya, GDP per capita has further decreased, because of the unrest and political and economic instability that the country is still experiencing. In 2010, before the end of the Gaddafi regime, per capita GDP was about $\$ 28887$, while in 2016 it had fallen to $\$ 7143$ (Table 1A.1).

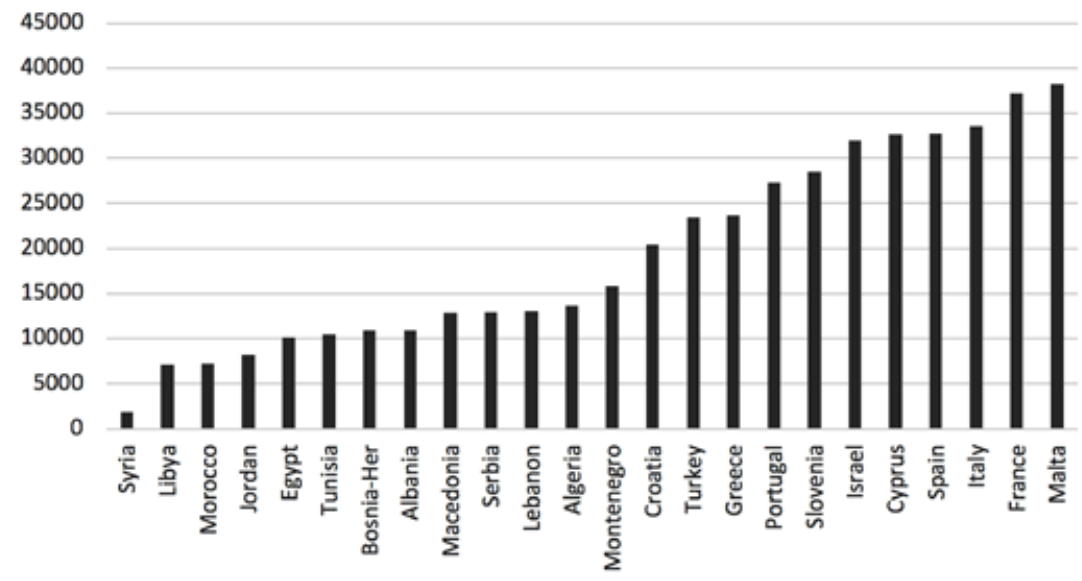

Figure 1.2 Per capita GDP in Mediterranean countries in 2016 (2010 USD)

Source: Our calculations based on IEA, Indicators for $\mathrm{CO}_{2}$ Emissions, data extracted on 21 December 2018.

In Southern Mediterranean countries, the share of the population below the minimum poverty line ( $\$ 1$ per day) is low, but increases drastically if the threshold of \$2 per day is taken (Ferragina and Nunziante, 2018). A large part of the population is therefore subject to the slightest negative shock, for example when food and fuel prices increase. Thus the per capita GDP decreases progressively as one moves geographically towards the Balkans, the Middle East and North Africa. Of interest is the case of Slovenia, which recovered immediately after independence, reaching a significant level of development. The economic crisis that began in 2008 had very negative effects on Greece and Portugal. Italy too has been struggling with low economic growth, high unemployment and high public debt. It may be stated that due to the recession and slow economic growth of the previous ten years, Italy's GDP has returned in real terms to the same levels as the late 1990s. In the Maghreb and in the Middle East, development rates declined, but the areas were less affected by the 2008 crisis. Starting from the end of the Gaddafi regime in 2011, Libya's real income suffered a dramatic contraction as a result 
of the civil war, which halted oil production and exports on which the Libyan economy depended. Indeed, according to International Monetary Fund (IMF) estimates, the hydrocarbon sector provided the Libyan economy with more than $90 \%$ of government revenues and export earnings (IMF, 2013).

Algeria was able to benefit from the rise in oil prices and natural gas, accounting for around $70 \%$ of government revenues. Despite the long civil wars, the problem of terrorism and Islamic fundamentalism, Algeria has experienced a major economic recovery, due especially to the high revenues from oil and natural gas exports, even though there has been a slowdown in growth rates in recent years.

In Egypt, after a period of intense growth, there was a slowdown due to the 2011 revolution, which led to the end of the Mubarak regime. Income from tourism has declined together with capital inflows, while the unemployment rate has increased.

Jordan experienced a period of intense development, with a GDP growth rate that reached an annual average of $6.7 \%$ in the period 2000-2006. Since 2010, growth rates have decreased significantly due to the international economic situation. Jordan has been hit by a series of severe shocks, such as conflicts in neighbouring Syria and Iraq, which caused considerable economic and social pressure (IMF, 2015). In the Mediterranean region, Jordan is considered one of the most open economies, and is heavily reliant on revenues from tourism, remittances from Jordanians' overseas and foreign investment, as well as being very dependent on foreign countries to meet its energy needs.

Since the recession of 2009 caused by the European crisis and the fall in domestic demand, Turkey has largely recovered thanks to far-reaching structural reforms implemented in the tax system and in the labour market. It is also one of the Mediterranean countries where population growth has been very intense, rising from 36 million in 1971 to 78 million in 2016.

There are also far-reaching divides in economic structures. The process of economic development generally involves a change in the weight of individual sectors, with a reduction in the agricultural sector and an increase in the industrial and service sectors. In the Mediterranean area, alongside the most advanced economies with a prevalence of industry and services, some countries show a delay in development, where agriculture continues to play a major role both in terms of workforce share and added value. By contrast, in the most advanced economies such as France, Italy and Spain, the service sector predominates both in terms of added value and numbers of employees. Indeed, in the above countries, agriculture accounts for merely $3-4 \%$ of the workforce, industry around $20-25 \%$, while services employ more than $60 \%$. The economic structure is completely different in North Africa where agriculture still accounts for a high share of the workforce, amounting to about 28\% in Egypt, and as much as 39\% in Morocco (Ansani and Daniele, 2014). In contrast, in 
oil- and natural gas-rich countries in North Africa, the main production activity is the exploitation of such natural resources.

In analysing inequality in Mediterranean countries it is important to distinguish between different periods. Ansani and Daniele (2014) show that from 1950 to 2000, inequality grew, arguing that, rather than economic convergence, Mediterranean countries experienced divergence. A period of decline occurred in the second half of the 1970s when the advanced economies of the North went through a period of crises due to the increase in oil prices, whereas the producing and exporting SEMCs such as Algeria, Libya, Egypt and Syria benefited from an increase in revenues thanks to the growth in oil revenues. However, from the early 1980s onwards, the gap increased once again and peaked at the beginning of the 1990s, remaining stable at these high levels throughout the decade. Contrary to expectations, a convergence process has taken place since 2001, thanks to the reduction in the gaps that returned to the levels of the early 1980s. The great crisis that began in 2007 hit European countries hard, especially Greece, Portugal and Italy, where there has been a contraction in GDP per capita, a reduction in production and an increase in unemployment, not only due to the crisis but also to restrictive fiscal policies. The sovereign debt crisis in Greece, Portugal, Spain and Italy has led to the adoption of restrictive fiscal policies which, added to the effects of the crisis, have produced recessionary effects on the economy, whose consequences have reflected in the levels of energy consumption. Thus from 2001 to 2011, differences between areas were reduced, not only because the growth rates of the countries lagging behind were higher but also because in the advanced countries there was a reduction in growth rates. Thus, in the Mediterranean region, convergence was achieved because the stronger countries declined and the weaker countries advanced (Bartoletto and Malanima, 2014).

However, because of the conflicts and serious unrest that began in 2011 with the so-called Arab Spring, in the countries of the Middle East and North Africa there has been a slowdown in growth rates. The still ongoing war in Syria and Libya made the picture even more complex. When Russia intervened in the war in Syria in September 2015, its goal was to ensure the survival of the Assad regime and to reduce US influence in Syria. After Russia's agreement with Turkey on 23 October 2019, Russia's "victory" in Syria was somehow sanctioned and an important role also for Turkey was envisaged. At the time of writing, the alliance between Putin and Erdoğan, consolidated after the attempted coup in Turkey in 2016, is also playing an important role in resolving the Libyan issue. The year 2020 started with growing concern at global level, because on 3 January a US raid on Baghdad airport in Iraq caused the death of Iranian general Qasem Soleimani, a key figure in the Ayatollah regime. On the night of 8 January a number of missiles hit the bases of Ain Al-Asad, one of the largest US installations in Iraq, and Erbil, the capital of Iraqi Kurdistan. 
Shortly thereafter, Tehran TV announced the start of the "Soleimani martyr" operation in response to the killing of the general. Iran carried out a massive offensive. At least 13 ballistic missiles left Tehran territory for US bases.

In Israel, the maximum alert was triggered and the price of oil on international markets immediately began to rise. To complicate the global picture there is the war in Libya, whose recent developments seem to be leading towards a division of its territories between Russia and Turkey. Indeed, on 10 December 2019, Turkish President Erdoğan announced his intention to militarily support the Libyan national agreement (GNA) government led by Fayez al-Sarraj against the military offensive of General Khalifa Haftar. And less than a month after its announcement, on 2 January 2020, the Turkish parliament authorized the sending of soldiers to Libya, approving the resolution with 325 votes in favour and 184 against.

\section{DYNAMICS OF TOTAL AND PER CAPITA ENERGY CONSUMPTION}

Increasing population and economic development has led primary energy consumption in the Mediterranean region to more than double, rising from about 393 million tons of oil equivalent (Mtoe) in 1971 to about 978 Mtoe in 2016 (Figure 1.3).

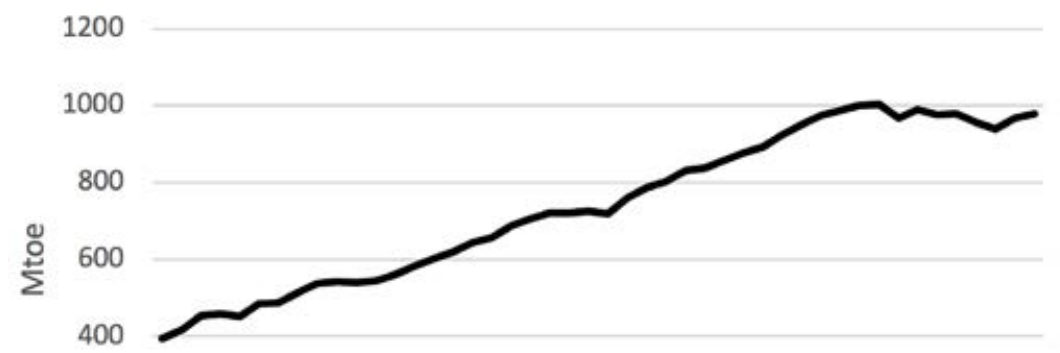

200

0

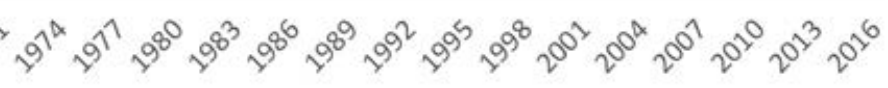

Figure 1.3 Total energy consumption in Mediterranean countries, 1971-2016 (Mtoe)

Source: Our calculations based on IEA, World Indicators, data extracted on 15 July 2019. 
The growth of energy consumption in the Mediterranean region is in line with global energy dynamics, since world energy consumption more than doubled during the same period of time, growing from 5523 in 1971 to 13761 Mtoe in 2016. However, the pace of growth has greatly diminished in recent years, and there is also a marked difference between the Organisation for Economic Co-operation and Development (OECD) and non-OECD countries: while in OECD countries there has been a reduction in the energy consumption rate, non-OECD countries have experienced a significant increase. Currently, OECD countries consume $38 \%$ of the world total, compared to $61 \%$ in the early 1970s. Much of the growth in energy consumption in the non-OECD group is due to China, which recently overtook the USA in terms of total energy consumption. There are several reasons that led to a reduction in energy consumption in OECD countries: first of all, the serious economic crises that hit the most advanced economies hard, causing a reduction in production and hence in energy consumption; but also other factors, such as improving energy efficiency and changes in the composition of the energy basket. A decisive contribution was made by the USA, where in recent years there has been a decrease in primary energy consumption thanks to the gradual replacement of coal with natural gas in electricity generation. However, the USA maintains a dominant position within the OECD countries, on its own accounting for $41 \%$ of the regional total, slightly less than in 1971.

The situation appears different if we consider per capita rather than total consumption: while the USA accounts for only $4 \%$ of the world's population, contrasting with China's $19 \%$, per capita consumption in the USA is about three times higher than in China. In 2016 per capita consumption in the USA was 6.69 toe, compared with 2.14 in the People's Republic of China. In general, the OECD countries are those that have the highest per capita consumption for different reasons: the very high level of electrification, which is close to $100 \%$, the larger number of cars per household, a very high GDP and a strong share of industry and services out of total GDP. Instead, the level of energy intensity (energy consumption by GDP) is below the world average. This is due to the high GDP, a growing level of energy efficiency, especially in transformation processes, from high efficiency in final consumption (machines that consume less fuel, better insulation of homes) and from relocation of high-energy intensity industries.

The divide between OECD and non-OECD countries is also reflected in the Mediterranean region. Indeed, North African and Middle Eastern countries have been affected by a sharp increase in energy consumption, triggered by consumer subsidies, which have caused overconsumption. The effects are levels of energy intensity higher than the worldwide average, and hence below-average energy efficiency (Jalilvand and Westphal, 2018), aside from higher $\mathrm{CO}_{2}$ emissions. In the countries of North Africa, total energy consump- 
tion rose more than tenfold, from about 18 Mtoe in 1971 to 185 in 2016 (Figure 1.4). While in 1971 North Africa represented only $4 \%$ of total consumption of the Mediterranean area, it currently represents $19 \%$ (Figure 1.5). On the other hand, while EU member states accounted for $81 \%$ of total consumption in 1971, by 2016 their share had fallen to 59\%. If we consider the Latin area in the strict sense (Italy, France, Malta, Portugal and Spain), the reduction is even greater, from $80 \%$ to $55 \%$.

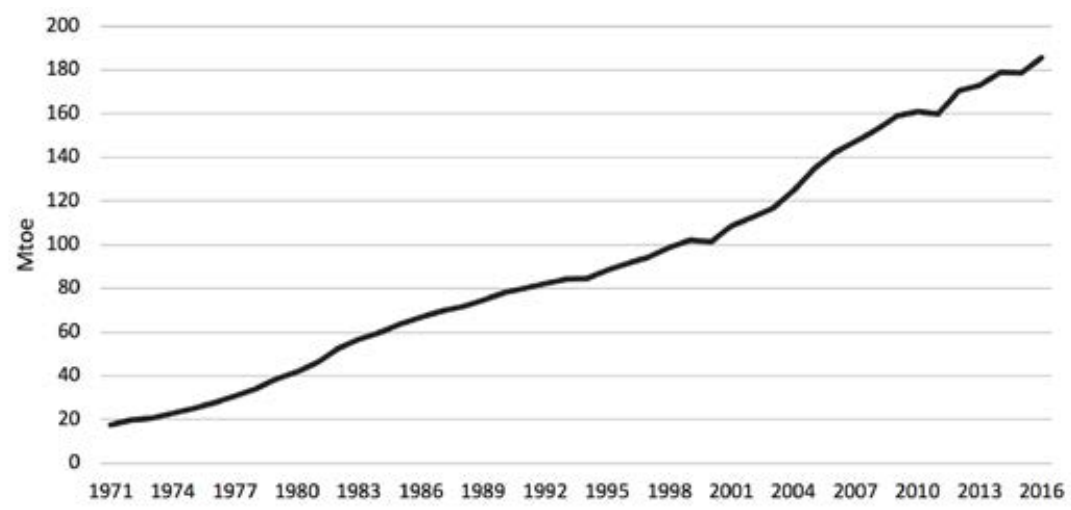

Figure 1.4 Total energy consumption in North Africa, 1971-2016 (Mtoe)

Source: Our calculations based on IEA, Indicators for $\mathrm{CO}_{2}$ Emissions, data extracted on 21 December 2018.

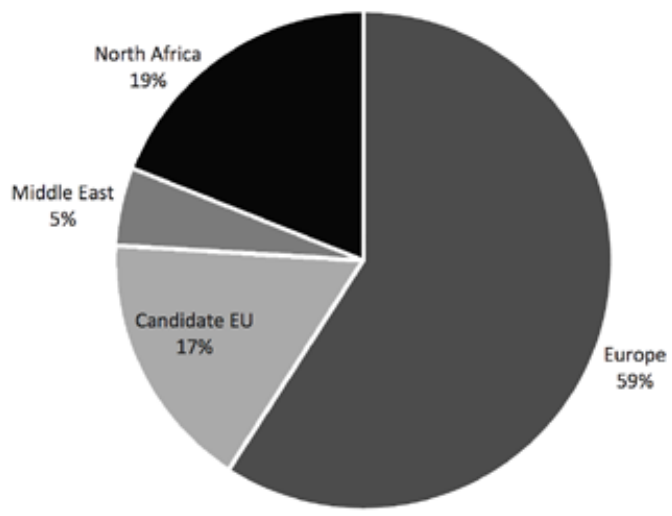

Figure 1.5 Total energy consumption in Mediterranean countries by macroregion, $2016(\%)$

Source: Our calculations based on IEA, Indicators for $\mathrm{CO}_{2}$ Emissions, data extracted on 21 December 2018. 
Different growth rates over time have led to a reduction between different macroareas of the Mediterranean region, since the non-OECD countries have recorded higher growth rates than the most advanced countries of the Latin area (Bartoletto, 2016a).

With regard to per capita energy consumption, the Mediterranean countries are very dissimilar. In the first ten positions of countries with the highest per capita energy consumption we find France, Slovenia, Israel, Spain, Cyprus, Italy, Libya, Serbia, Portugal and Greece (Figure 1.6).

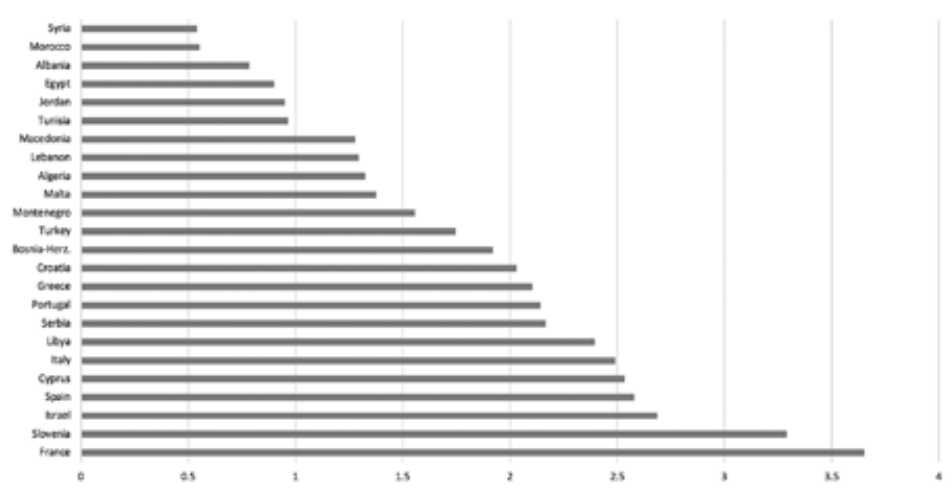

Figure 1.6 Per capita energy consumption in 2016 (toe)

Source: Our calculations based on IEA, World Indicators, data extracted on 2 January 2019.

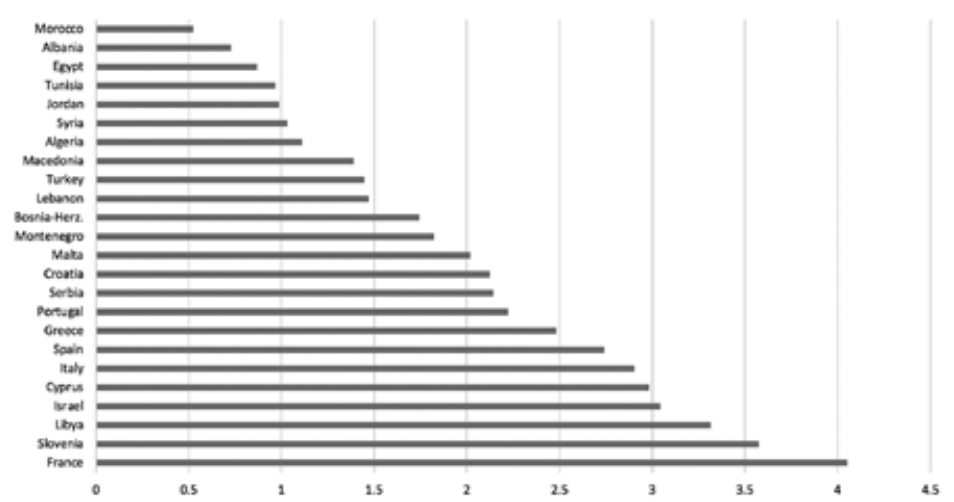

Figure 1.7 Per capita energy consumption in 2010 (toe)

Source: Our calculations based on IEA, World Indicators, data extracted on 2 January 2019. 
The gaps in per capita consumption levels are considerable. In France per capita consumption is 10 times higher than in Morocco, which is the country with the lowest per capita consumption, along with Syria (Figure 1.6). Not only is there a divergence between the countries of the North and those of the South, but even within the individual areas the differences are considerable. In the North Africa region, Libya had the highest levels of per capita energy consumption throughout the period analysed (Figure 1.8). The growth was very rapid after the discovery of huge oil reserves at the beginning of the Gaddafi regime in 1969, which made Libya the richest country in the North African region in terms of GDP per capita. Following the spread of the Arab Spring and the end of the Gaddafi regime in 2011, per capita energy consumption fell drastically, together with GDP per capita. Since the collapse of oil and gas production, which represented almost the only source of revenue, the ongoing serious internal unrest has not allowed the country to kickstart its recovery. Yet despite the substantial decrease in energy consumption, Libya is still the country with the highest levels of per capita energy consumption among its North African neighbours. Indeed, from Figure 1.8, there is an evidently large divergence with Algeria, Egypt, Morocco and Tunisia, whose per capita energy consumption lagged far behind. Algeria ranks second in terms of such energy consumption, followed by Tunisia, Egypt and, last of all, Morocco.

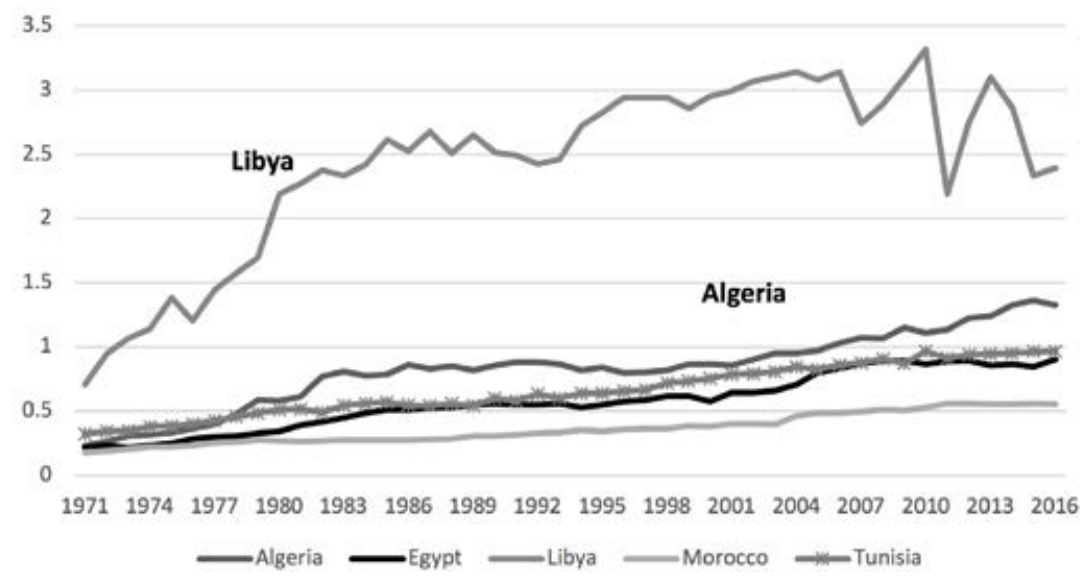

Figure 1.8 Per capita energy consumption in North African countries, 1971-2016 (toe)

Source: Our calculations based on IEA, World Energy Balances, data extracted on 21 December 2018. 
The same applies to Syria, where the economic picture has radically changed in recent years, following the outbreak of war. It is notable that before the war, per capita energy consumption in Syria was higher than that of Egypt, Tunisia or Jordan (Figure 1.7).

In order to ascertain whether the gap between the different countries is narrowing, we calculate the Gini index on per capita energy consumption, considering the period 1971-2016 (Figure 1.9). The Gini index is the most common statistical index of diversity or inequality to measure the dispersion of a distribution in ecology and social sciences. It is also widely used in econometrics as a standard measure of inequality in income and wealth. It ranges from 0 , which represents perfect equality (all measurements are equal), to 1, which represents the maximum degree of inequality (Gini, 1921; Bellù and Liberati, 2006). Inspection of Figure 1.9 shows that the Gini index, calculated on per capita energy consumption of each Mediterranean country, has decreased over time. The variation range fell from 0.41 in 1971 to 0.28 in 2016. Estimation of the index confirms that the reduction of the gap concerns not only total energy consumption, but also per capita energy consumption. It may thus be argued that the growth in total consumption in North African and Middle Eastern countries is not only due to population growth, but also to an increase in per capita consumption.

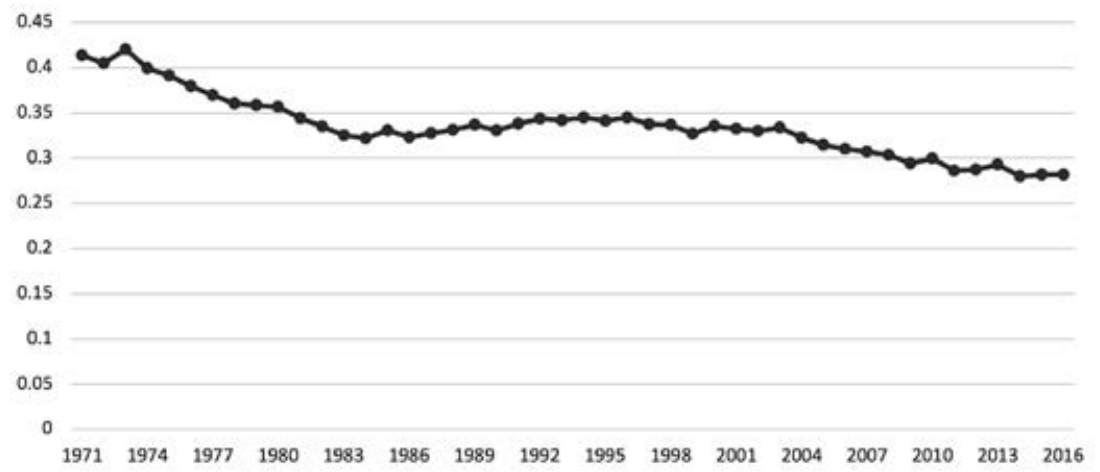

Figure 1.9 Gini index on per capita energy consumption, 1971-2016

Source: Our estimates based on IEA, World Energy Balances, data extracted on 21 December 2018.

The above results may be explained by considering changes in the energy basket over the years. Since the energy transition has led to a reduction in consumption of traditional sources and an increase in modern sources, in the countries on the southern and eastern shores of the Mediterranean, which are 
less industrialized than those on the northern shore, this process of substitution occurred later and, in recent decades, there has actually been a convergence in the consumption of modern energy sources.

On calculating the growth rates of the Gini index, it emerges that, with reference to the per capita energy consumption, the narrowing of the gaps between the Mediterranean countries was considerable between 1971 and 1981. During this decade, the gap decreased by about $16 \%$. There are several reasons that could account for this trend. On the one hand, the richest countries in Mediterranean Europe were experiencing a serious economic and financial crisis due to the oil crisis and the serious monetary disruption created by the end of the Bretton Woods system. On the other, the North African and Middle Eastern countries were thriving on the rich proceeds from oil exports and consuming increasing amounts of fossil fuels. In the following decade 1981-1991, the growth rate fell back drastically, with the gaps in per capita energy consumption continuing to decrease, but at an estimated average rate of $1.7 \%$. During this phase, the negative consequences of previous conflicts were felt, such as the war between Israel, and Egypt and Syria. The difficult situation led to a reduction in oil exports and related income, which all had repercussions on narrowing the gap between the richest and poorest countries in the Mediterranean. In the following decade 1991-2001 the reduction in the gaps in terms of per capita consumption continued, but at a slightly lower annual average rate of $1.6 \%$. This was due above all to the recovery of energy consumption in the countries belonging to the Latin area. However, the dynamics of per capita consumption are also affected by the severe economic crisis in the countries that form part of the Adriatic area. Albania, subjected from 1928 to the Italian fascist regime, regained its independence in 1944, being subsequently governed for decades by a strict communist regime. In 1990, the severe internal economic crisis fuelled a strong popular protest, which led to the end of the previous regime, also due to the collapse of the Soviet Union. A process of transition towards parliamentary democracy was therefore initiated which was far from smooth, fuelling in the process mass migratory phenomena, and resulting in a political and social crisis that led to an armed uprising. The intervention of a United Nations (UN) military mission in 1997 allowed the country to stabilize and political elections to be held. Since then in Albania there have been successive centre-right and centre-left governments. Albania is currently one of the candidate countries to join the EU.

However, also the break-up of the Yugoslav Socialist Republic, which was established in 1945, contributed to slowing the narrowing of the gap. Slovenia, formerly part of the Yugoslav Socialist Republic, declared itself independent in June 1991, and obtained recognition from the international community in January 1992. In 2004 it joined the EU, and in 2007 it adopted the euro. The break-up of the former Yugoslavia left many unresolved issues among the 
republics that formed part of it. Croatia, also part of the former Yugoslavia, declared itself independent in June 1991, and was recognized by the international community in October of the same year. This led to a bitter conflict with the Serbian minority calling for independence. From 1992 to 1995 Croatia participated in the conflict in Bosnia and Herzegovina. The latter declared its independence on 9 January 1992. The same year a bloody civil war began between Croatian, Bosnian-Muslim and Serbian nationals, only ending after the intervention of the UN and NATO. Macedonia, also a federated republic within Yugoslavia, declared its independence on 15 September 1991, though only achieving recognition by the international community in 1993, under the name of the Former Yugoslav Republic of Macedonia (FYROM).

In conclusion, the recovery in energy consumption of European countries and the crisis in the countries belonging to the Adriatic area impacted on the dynamics of the gap between the most advanced and the least advanced countries in the decade from 1991 to 2001. The gap narrowed considerably during the following decade (2001-2010), the average annual reduction being estimated at $13 \%$. Energy consumption is increasing in the economies of North Africa and the Middle East, and the process of replacing conventional sources of energy with so-called modern sources continues, especially in Morocco and Tunisia. At the same time, however, the most advanced economies are in recession due to the 2007 crisis, which led to a reduction in energy consumption.

Our estimates of the Gini index conclude with the analysis of the last period for which we have data available, that is, the years from 2011 to 2016. The reduction in the gap continues, but the relative rate falls to $1.6 \%$. The so-called Arab Spring, which broke out in 2011, affected energy consumption. Started with the aim of opposing dictatorships and spreading democracy, it ultimately proved to be a failure, since it led to conflict, internal turmoil and the disruption of oil and gas production.

\section{ENERGY CONSUMPTIONS BY FUEL}

The composition of the world energy balance has considerably changed over time. Oil remains the main energy source in the world, although its share has declined from $44 \%$ in 1971 to $32 \%$ in 2016 . The reduced share of oil as an energy source is to be explained by the increase in other energy sources: first natural gas and then nuclear and coal. Although conventional oil still plays a prominent role, the pace of discovery has plunged in the last decade. Thus there is an over-reliance on existing reserves to satisfy future demand.

It is believed that the rapid entry into operation of shale oil deposits in the USA, combined with technological progress, will make it possible to meet future demand. However, according to some estimates, shale oil will continue 
to represent a mere $10 \%$ of the global oil market. Conventional oil will therefore continue to play a key role.

With regard to the pace of conventional oil discoveries, between 2000 and 2014 an average of 10 billion barrels a year were discovered. However, in the last three years this amount has fallen to just 3 billion due to the reduction in exploration spending (Chauhan and Sen, 2018). Producers justify the fall in the reserves to production ratio by claiming that the industry no longer needs a large reserve margin, which would constitute an inefficient use of capital. The exhaustion of oil wells and their decline are two fundamental aspects of the debate on the future of the oil supply. Rates of decline and exhaustion are interconnected but are not the same thing. Rates of decline refer to the annual reduction in the rate of production from a field after it has reached its peak production. The rate of exhaustion instead refers to the rate at which oil is produced by a reservoir, expressed as an estimate of the fraction of the extractable quantity (estimated ultimate recovery-EUR) or of the remaining reserves. Generally an oil field begins its declining phase after $40 \%$ of its reserves have been extracted. Future increasing demand cannot be satisfied by relying only on existing reserves. About $70 \%$ of non-OPEC reserves have been exploited and it is expected that in the following decades the exploitation rate will be higher than that deemed sustainable. The decline in oil consumption at world level has been partially offset by natural gas, whose consumption increased from $16 \%$ in 1971 to $22 \%$ in 2016 (Figure 1.10). In the USA, gas electricity generation grew from $18 \%$ in 2005 to $31 \%$ in 2017. Also in Europe, the role of gas in electricity generation has significantly increased over time. Unlike the oil market, the gas market will continue to be oversupplied for the next few years. However, forecasts are changing rapidly due to the growth in gas consumption. Thus the coming years are likely to see an absorption of the overcapacity of past years. The growth in demand will depend on the emerging countries of Asia and above all China. The Middle East is also highly likely to play a leading role.

The main drivers of the increase are industry and electricity generation. In recent years, the market has been revolutionized by non-conventional gas, namely shale gas, the natural gas stored in porous rocks, which it has become possible to extract thanks to the progress of technology, especially fracking - with which liquids are injected into rocks with high-pressure jets - and horizontal drilling. Shale gas represents more than half of the new reserves ascertained today and in the USA it has increased the resources available threefold. In Europe the most significant deposits are believed to be in Poland and France. Shale gas and also shale oil, both of which are hydrocarbons contained in shale rocks, have been the main protagonists of the energy "revolution" in recent years. In addition to purely energy-based importance, the exploitation of these unconventional sources has had far-reaching political 
and economic implications worldwide. The first to realize the potential of this resource was the USA which, once the appropriate technology was developed, began to extract it. In just a few years the production of such unconventional hydrocarbons has allowed the USA not only energy independence but also the possibility of exporting surplus gas and oil abroad, with "side-effects" on all the world's energy markets. This huge quantity placed on the market has produced, at the global level, since mid-2014, a fall in the price of crude oil. Only recently have OPEC and non-OPEC countries (especially Russia) found measures to counteract this oversupply with an agreement to cut production.

Although coal is the most polluting fossil fuel, it continues to be the second most important energy source globally, accounting for a $27 \%$ share of total energy sources in 2016. Nonetheless, in the USA coal-based electricity generation decreased from $40 \%$ in 2014 to $31 \%$ in 2017 , to the advantage of gas. The important position of coal consumption at world level stems largely from the increased demand from China, which has continued to invest in power plants fuelled by coal for electricity production. China currently produces about $45 \%$ of the world's total, followed, at a considerable distance, by India, with $9.7 \%$, and the USA, with a share of $9.3 \%$. Yet there is also a resurgence of coal consumption in other countries such as Germany, which in recent years has implemented the production of lignite, the most polluting coal. Germany is currently ranked eighth in the world for coal production.t

Nuclear energy represents about $5 \%$ of total demand, four percentage points more than in 1971, although several governments have announced their aim to close down nuclear power plants following the Fukushima disaster in 2011. The main producer is the USA, which accounts for 840 TWh of nuclear electricity, amounting to $32 \%$ of world nuclear electricity production. 1 France is second in the world ranking with a production of $403 \mathrm{TWh}$ and a share of $17.2 \%$ of the world total. The People's Republic of China comes third, with a production of $213 \mathrm{TWh}$ of nuclear electricity, corresponding to $8 \%$ of the world total. In fourth position is the Russian Federation, with a production of 197 TWh and a share of about 7\%. Germany continues to be in the top ten of producing countries, although the German government declared soon after the Fukushima disaster its objective to reduce nuclear production. It now produces $85 \mathrm{TWh}$, corresponding to about $3.3 \%$ of world total.

Despite the extensive debate on climate change and the negative consequences for the environment of fossil fuels and nuclear consumption, renewable energy at world level represents only $14 \%$ of total consumption, only one percentage point more than in 1971 (see Figure 1.10). This represents a disconcerting contradiction between what the governments of the various countries announce and what is then concretely done in terms of investments in renewables (Clô, 2017), even though in some countries major efforts have been made to achieve greater protection of the environment. 


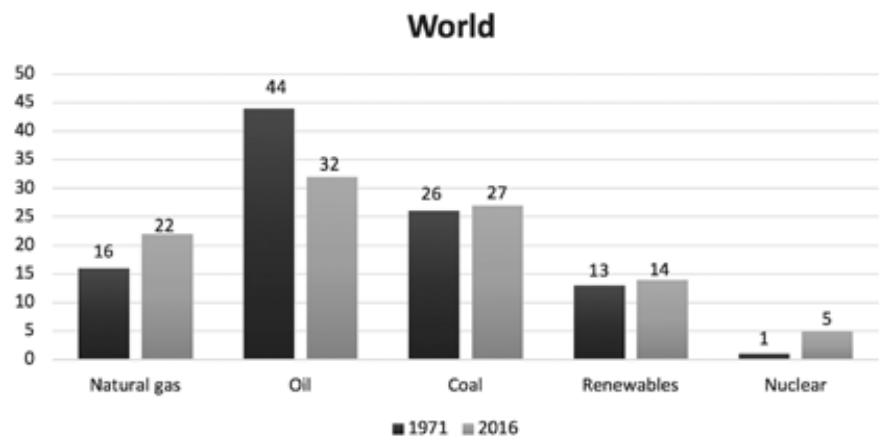

Figure $1.10 \quad$ World energy consumption by fuel, 1971 and $2016(\%)$

Source: IEA, World Energy Balances, data extracted on 20 November 2018.

The energy balance in the Mediterranean region is somewhat different: coal plays a more limited role, and there has been significant progress in renewable energy, even though there are major differences between and within different areas (Figure 1.11). Indeed, the rapid growth of fossil fuel consumption in the developing countries of North Africa and the Middle East has made the Mediterranean's share of renewable energy lower than its global counterpart.

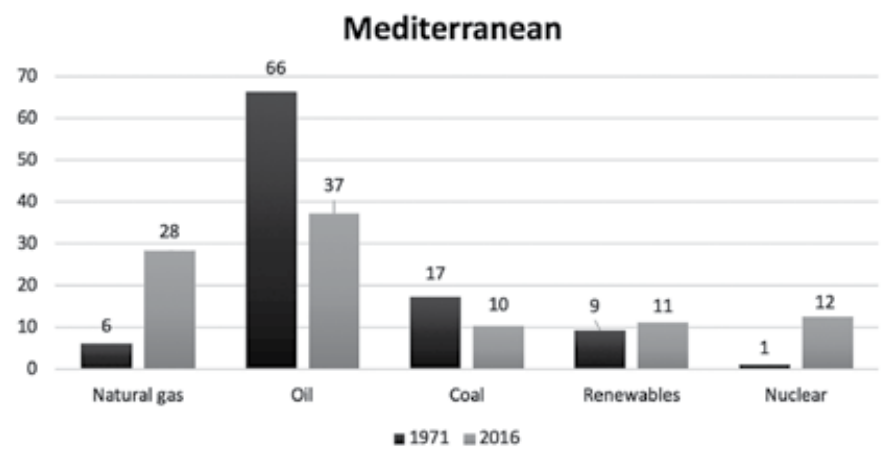

Figure 1.11 Energy consumption by fuel in the Mediterranean region, 1971 and $2016(\%)$

Source: Our calculations on IEA, World Energy Balances, data extracted on 20 November 2018. 
The energy balance of the Mediterranean region is also dominated by fossil fuels, which make up $76 \%$ of total primary energy consumption (Figure 1.11). Oil remains the main energy source, with a $37 \%$ share of the total, even though over the years its consumption has decreased in both absolute and relative terms. The share of natural gas increased from $6 \%$ in 1971 to $28 \%$ in 2016 , while that of coal decreased from $17 \%$ to $10 \%$ (Figure 1.11). Analysing oil consumption from 1971 to today, we note that the peak was reached in 2006 (Figure 1.12), with a consumption of 416594 kilo tons of oil equivalent (ktoe). Its consumption then decreased, falling to 363949 ktoe in 2016. Natural gas consumption has increased considerably. In 1971, its consumption was only 24193 ktoe, but following the oil crises of 1973 and 1979, its consumption grew very rapidly in the Mediterranean region, peaking at 277482 ktoe in 2010. Subsequently, as a result of the 2007 crises, natural gas consumption started to decrease, but after the low of 263861 ktoe in 2014, it rose to 281950 in 2016 (Figure 1.12).

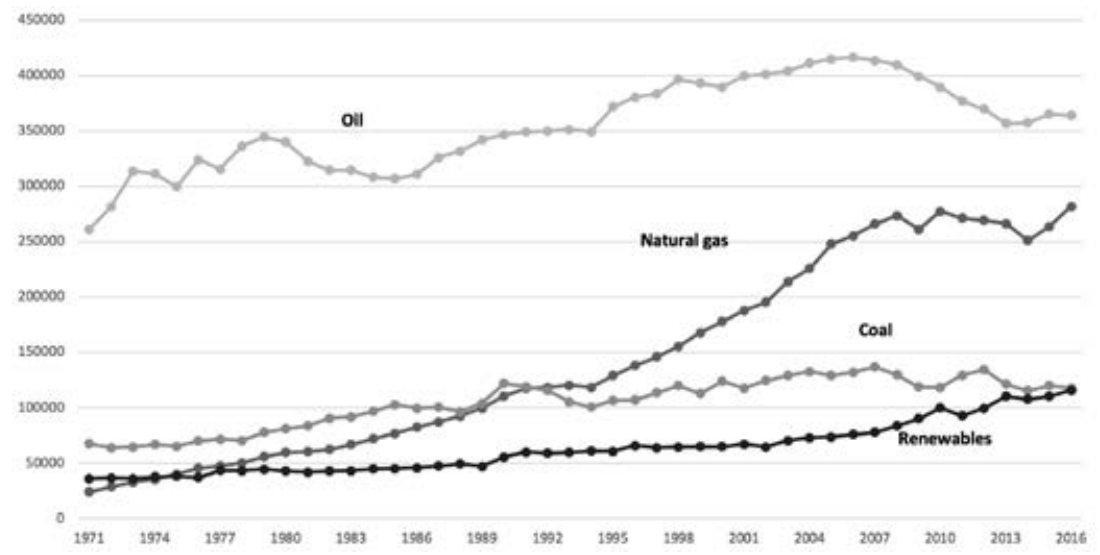

Figure 1.12 Consumption of renewables and fossil fuels in Mediterranean countries, 1971-2016 (ktoe)

Source: IEA, World Energy Balances, data extracted on 20 November 2018.

Coal instead satisfies only $10 \%$ of total demand, a value well below the world average (Figure 1.11). Coal consumption is mainly concentrated in Turkey, Israel, Morocco and former Yugoslavia, which have the highest proportion of coal consumption with respect to the other countries of the Mediterranean region.

The growth of nuclear electricity was remarkable in the Mediterranean region after the oil crises. Indeed, nuclear rose from $1 \%$ of total energy 
consumption to $12 \%$, and now represents the third energy source in order of importance. Yet about $86 \%$ of nuclear consumption is concentrated in France, which represents at global level the country with the highest percentage of nuclear-generated electricity. Due to France alone, the percentage of nuclear consumption in the Mediterranean region is well above the world percentage. As a result of the massive use of nuclear energy, in France the consumption of oil has been significantly reduced, not only in percentage terms compared to other energy sources, but also in absolute terms. In 1992 nuclear consumption overtook oil consumption and the gap has continued to widen ever since. The use of nuclear power has allowed France not only to drastically reduce its energy dependence on fossil fuels, but also to reduce its electricity costs: in France, the cost of one kWh of electricity is as much as $40 \%$ lower than in Italy, which has no nuclear option in its energy basket.

Within the Mediterranean region, apart from France, only two other countries have nuclear power plants: Spain, which has eight nuclear power plants, and Slovenia, which has only one. In 1964, the leading Spanish electricity company began an ambitious project to construct nuclear power plants. Twenty years later, Spain was one of the most nuclearized countries in the world. A crucial role was played by US companies. The Spanish utilities decided to import US nuclear technology largely because of the financial facilities granted by US public and private institutions (Rubio-Varas and De la Torre, 2017).

In Slovenia there is the Krsko nuclear power plant, the result of a joint venture between Slovenia and Croatia (which at the time were part of the former Yugoslavia). The nuclear power plant was connected to the electricity grid in October 1981, but became operational only in January 1983.

In Italy, by contrast, much emphasis has been placed on natural gas, which accounts for about $60 \%$ of the production of electricity, and an energy basket dominated by the most expensive energy sources. Italy pursued a completely different energy policy, abandoning nuclear power in 1987. During the 1960s and 1970s nuclear schemes received considerable investments and met with great favour from the public at large, such that Italy gained a significant position in the world for the production of electricity of nuclear origin. The first power plants built were those of Latina (1963) and Garigliano (1964). With the entry into operation of the Trino Vercellese nuclear plant in Northwest Italy in 1965, the first phase of the industrial development of nuclear energy in Italy was completed. This expansive cycle was to be concluded with the activation of the Caorso plant in the Po Valley in 1980.

Italy's decision to build nuclear power plants, with the technologies available at the time, in the same period in which they were constructed in the USA and USSR, stemmed not only from the need to satisfy the growing demand for energy. In the middle of the Cold War with the Soviet Union, the 
USA influenced the nuclear policies of European countries struggling with post-war reconstruction supported by the Marshall Plan. For the procurement of fuels for power plants, Italy (like Japan) would also be linked to an even greater dependence on the USA (Rubio-Varas and De la Torre, 2017). Yet in 1986, with the explosion of a reactor at the Chernobyl nuclear power plant in Ukraine, a critical consensus concerning nuclear energy arose. In Italy, implementation of part of the National Energy Plan, which provided for the opening of construction sites for new nuclear power plants, was blocked. In any event, with the 1987 referendum, Italy's electorate voted overwhelmingly to abandon the use of nuclear power as a form of energy supply. The referendum led to the closure of the nuclear power stations then in operation. After the end of its nuclear adventure, Italy focused heavily on natural gas, of which it is the largest consumer in the Mediterranean region.

In 2008, the Berlusconi government announced the resumption of nuclear power. The new nuclear programme envisaged the construction of four third-generation nuclear power plants by 2020 , with a production of 6000 MW, in order to cover at least $10 \%$ of energy consumption in Italy. After the Fukushima disaster in 2011, Italy again abandoned its nuclear project through a new referendum, and decided to implement its policies in the gas sector, which imports from Russia and Algeria. Analysts believe that it was risky enough to focus so heavily on gas, since this means a strong dependence on its imports. This problem came to prominence on 1 January 2006, when the crisis began between Russia and Ukraine, a crisis that intensified again in January 2008 with the blocking of gas supplies by Russia. Relations between Russia and Ukraine have worsened following the 2014 referendum on the annexation of Crimea to Russia, and the tensions between the two countries are currently at the highest level.

In the Mediterranean region, renewable energy represents only $11 \%$ of total energy consumption, about three percentage points lower than the world level. Yet during the last decade, there has been significant progress in renewable energy within the Mediterranean region. Indeed, until 2009 renewables played a more marginal role, representing only $8 \%$ of the total. Changes in the energy balance of the Mediterranean region accelerated after the 2007 crisis. Renewable energy grew by $46 \%$ between 2007 and 2009. By contrast, oil consumption fell further, from $40 \%$ in 2009 to $37 \%$ in 2014 , and $36 \%$ in 2016. This means that during the years when the effects of the crisis were felt more strongly in Europe and in the Mediterranean countries, the energy balance changed to the benefit of renewable energy, whose share has grown, while the overall contribution of fossil fuels decreased from $80 \%$ in 2007 to $76 \%$ in 2016.

It is also important to distinguish the energy balance within the single macroareas. In the Latin area, oil consumption increased from the 1960s, reaching 
its peak in the 1970s. Subsequently, in the 1980s, it suffered a sharp contraction and then settled on lower levels. After the economic crisis of 2007-2008, it again fell significantly. Yet the trend in other Mediterranean areas was different. In the Anatolian-Balkan area, in the Maghreb and, finally, in the Middle East, oil consumption has increased significantly since the 1970s. In particular, in the Maghreb, oil consumption has also risen in recent years. In the Anatolian-Balkan area, it has declined sharply since 2007. This decline has affected not only Greece, devastated by the serious economic crisis, but also Turkey, which has instead increased its consumption of coal. There was a sharp reduction in oil consumption in Libya due to events related to the end of the Gaddafi regime. After the peak of 14540 ktoe in 2010, oil consumption plunged to 8981 ktoe in 2011. Then there was a recovery in 2012 and 2013, only to decline thereafter. In 2016, oil consumption stood at $10717 \mathrm{ktoe}$. The chapters that follow investigate different energy balances by macroarea, with a special focus on $\mathrm{CO}_{2}$ emissions.

\section{NOTES}

1. IEA, Indicators for $\mathrm{CO}_{2}$ Emissions, data extracted on 21 December 2018.

2. Namely: Algeria, Egypt, Israel, Jordan, Lebanon, Libya, Morocco, Palestine, Syria, Tunisia and Turkey.

3. IEA, Indicators for $\mathrm{CO}_{2}$ Emissions, data extracted on 21 December 2018.

7. https://www.ecfr.eu/rome/post/laccordo_della_russia_con_la_turchia_sulla_siria settentrionale, accessed on 10 January 2020.

5. IEA, World Energy Balances, 2018.

6. IEA, Key World Energy Statistics, 2018.

IEA, World Energy Balances, 2018.

European Parliament, 2014.

9. IEA, World Energy Balances, 2018.

10. IEA, Key World Energy Statistics, 2018. Data for coal production are 2017 provisional data.

11. IEA, Key World Energy Statistics, 2018. Data for nuclear electricity production refer to 2016. 